\title{
Sexual rights, mental disorder and intellectual disability: principles and law
}

\author{
Isabelle Le Gallez, Keith J. B. Rix, Kartina A. Choong \& Helen Dewson
}

Isabelle Le Gallez is due to complete her LLM in Medical Law and Ethics at the University of Edinburgh, having graduated from the University of Sussex with her LLB in Law, and she is about to commence a PhD. Keith Rix is an honorary consultant forensic psychiatrist, Norfolk and Suffolk NHS Foundation Trust, and Visiting Professor of Medical Jurisprudence, University of Chester, where he is involved with its MSc in Medicolegal Practice. He is an elected Honorary Fellow of the Faculty of Forensic and Legal Medicine of the Royal College of Physicians. Kartina Choong is a Reader in Medical Law and Ethics at the University of Central Lancashire. She is a non-practising barrister and an accredited mediator. She is a

Fellow of the Higher Education Academy. Helen Dewson has an LLM in Mental Health Law from Northumbria University and currently works as a legal practice advisor for a mental health trust. She also sits as a specialist lay member of the Mental Health Tribunal.

Correspondence Isabelle Le Gallez, Edinburgh Law School Postgraduate Office, Old College, South Bridge, Central Campus, Edinburgh EH8 9YL, UK.Email:s1774482@sms.ed.ac.uk

\section{Copyright and usage}

(C) The Royal College of Psychiatrists 2018

\footnotetext{
${ }^{a}$ We use the term 'intellectual disability' in this article but when quoting from literature, case law and mental health legislation, we use no longer acceptable terminology such as 'feeble minded', 'moral defective' and 'mental handicap'; note that 'learning disability' is commonly used in UK legislation and health and social care.
}

\section{SUMMARY}

People with mental disorder and intellectual disability have the same rights to sexual expression as other people, albeit that in some cases a lack of capacity may require curtailment of those rights and regard must be had to protecting the vulnerable. Furthermore, the formation or maintenance of sexual relations, or the attainment of sexual fulfilment, may assist in the maintenance or restoration of mental health or well-being. This article demonstrates how the courts in England and Wales, applying statute law and judicial precedent, are largely supportive of the rights of people with mental disorder or intellectual disability to make decisions about sexual expression, sexual relationships and related matters, notwithstanding some societal and staff attitudes that act to prevent them fulfilling their sexual needs and making decisions about sexual and reproductive matters.

\section{LEARNING OBJECTIVES}

- Understand the underlying principles that apply to the exercise of their sexual rights by people with mental disorder or intellectual disability

- Understand some of the obstacles to the exercise of sexual rights by people with mental disorder or intellectual disability

- Understand the statute and case law that apply to the exercise of sexual rights by people with mental disorder or intellectual disability

\section{DECLARATION OF INTEREST}

None.

\section{KEYWORDS}

Intellectual disability; human rights; ethics.

'To be a human being is to be a sexual being' Craft (1987: p. 19)

At least for the time being, the survival of the human race depends on sexual intercourse between the males and females of our species. But a satisfying and pleasurable sexual life is also important to people in same-sex relationships and it may be important to people who are not in a sexual relationship with another person, whether temporarily or for life.

In this first of two articles (see also Dewson 2018), we identify the right to sexual expression and related rights; we set out their underlying principles; we describe some obstacles to their expression; and we describe how the law in England and Wales, through judicial precedents and statutes, addresses issues relating to their exercise.

\section{'The right to pursue a satisfying, safe and pleasurable sexual life'}

\section{Principles}

In 2006, following 'a consultation process with international experts', the World Health Organization (2006: p. 5) recognised 'sexual rights' as embracing 'human rights that are already recognized in national laws, international human rights documents and other consensus statements'. They include the right to 'pursue a satisfying, safe and pleasurable sexual life' (Box 1).

The exercise of such rights depends on the application of the fundamental bioethical principle of a respect for autonomy. This depends on two essential conditions: liberty or independence from controlling influences; and agency or the capacity for intentional action (Beauchamp 2013: p. 102). These conditions find their application in the law. As Baroness Hale stated in $R$ v $C$ [2009], 'Autonomy entails the freedom and the capacity to make a choice'. However, where mental disorder or intellectual disability $^{\mathrm{a}}$ compromises capacity, the exercise of a right, such as the right to pursue a sexual life, may have to be curtailed in the person's best interests.

People with mental disorders or intellectual disabilities have the same rights as other human beings. This is as true of the patient with mental disorder or intellectual disability detained without limit of time in the single-sex ward of a high-security hospital as it is of the psychiatric out-patient with mental disorder who goes home from the clinic appointment to his or her lifelong sexual partner, or the married couple who both have intellectual disabilities. The right to a sexual life exists irrespective 
of the capacity to exercise autonomy, although if capacity is compromised this may affect the extent to which the right can be exercised.

\section{Practice}

Health professionals acknowledge this right to pursue a sexual life when they formulate care plans based on Maslow's hierarchy of needs (Maslow 1943, 1954) or apply the 'good lives model' of rehabilitation (Yates 2011: p. 10), in which one of the 'primary goods' is 'Relatedness (intimate, romantic and family relationships)'. However, entries such as 'married' or 'gay' when recording 'sexual intimacy' under 'Love and belongingness needs' or 'Relatedness' categories on care planning documents suggest both an unwillingness, perhaps born out of embarrassment or mistaken assumptions about confidentiality or privacy, to enquire about a patient's sexual life, and a belief that this is not something that requires any further consideration when planning the maintenance or restoration of mental health and well-being. Yet, as Maslow (1943) recognised, sexuality is predominantly linked to one of the human race's basic needs, that of 'love'. Tennille $\&$ Wright (2013: p. 3) have pointed out that 'the desire to enter into emotionally satisfying and sexually intimate relationships and to maintain such relationships underpins adult experience.' What Craft (1987: p. 23) said about people with 'mental handicaps' applies also to people with mental disorder:

'Relationships give spice and add interest to all our lives. They carry with them both the delights of loving, sharing and caring, and the risk of sorrow, sadness and hurt; but that is all part and parcel of human existence, of personal growth and development. While we can and should offer guidance and counselling, we cannot and should not protect those with mental handicaps from every relationship risk.'

So, sexual expression for many people with mental disorders or intellectual disabilities cannot be separated from the overall goal of enabling them to achieve, maintain, recover or repair their relationships with their fellow human beings.

Ensuring that people with mental disorders or intellectual disabilities do not suffer a denial or curtailment of their 'right to pursue a satisfying, safe and pleasurable sexual life' (World Health Organization 2006) or any other sexual rights, represents an enormous challenge to mental health and intellectual disability services. Beauchamp $\&$ Childress (2013: p. 101) define personal autonomy as 'at a minimum, self-rule that is free from both controlling interference by others and from limitations, such as inadequate understanding, that prevent meaningful choice'. However, the care of people with mental disorder can easily extend to a
BOX 1 Sexual rights as defined for the World Health Organization

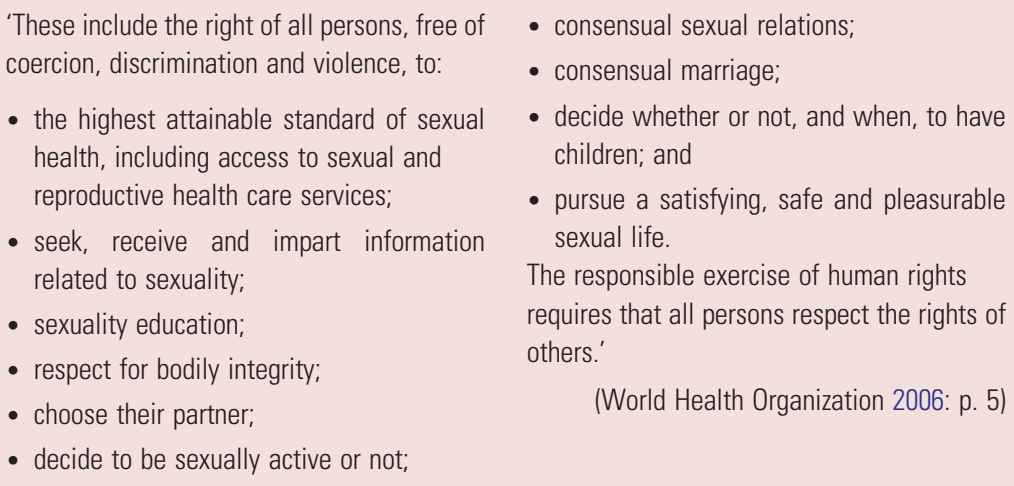

controlling interference with their sexual rights, which is not justified unless they lack the capacity to exercise such rights or unless the interference can be justified under Article 8(2) of the European Convention on Human Rights 1950 (ECHR), which allows a public authority to interfere with a right if it is 'in accordance with the law and is necessary in a democratic society in the interests of [...] public safety [...] for the prevention of disorder or crime, for the protection of health or morals or for the protection of the rights and freedoms of others'. Munjaz v United Kingdom [2012] emphasised the principle of personal autonomy and ruled that persons detained under the Mental Health Act 1983 were presumed to enjoy all the fundamental rights and freedoms guaranteed by the ECHR, except the right to liberty, and that any restriction of those rights had be justified in each individual case. Likewise, the care of people with intellectual disability can easily create circumstances in which a capacitous intellectually disabled person does not acquire, or may be denied, the adequate understanding necessary to make the meaningful choices in sexual matters that they should be enabled to make.

\section{Barriers}

'Feeble-minded women are almost invariably immoral, and if at large usually carriers of venera [sic] disease or give birth to children who are as defective as themselves [...] Every feeble-minded person, especially of the high grade, is a potential criminal needing only the proper environment and opportunity for the development and expression of his crimina tendencies' (Fernald 1893).

Such beliefs formed part of the rationale in Victorian times for locking up the intellectually disabled in institutions, where they were deprived not just of their liberty but of the opportunity for forming sexual relationships. Until the Mental Deficiency Act 1913 was replaced by the Mental Health Act 1959, many unmarried mothers were classified 
as 'moral defectives' and detained in mental institutions. So well established was this that the Mental Health Act 1959 (and its successor, the Mental Health Act 1983 as amended in 2007) had to make it clear that no one could be dealt with under the Act as suffering from mental disorder 'by reason only of promiscuity or other immoral conduct' (s.4(5)). sexuality have been projected onto people with learning disabilities', resulting in stereotypes of them being either 'asexual or oversexed, innocents or perverts'. There is an assumption that people with major mental illnesses are asexual (McCann 2000). Such assumptions are both conceived and propounded or influenced by society. Aunos $\&$ Feldman (2002) reported that up to $80 \%$ of parents and service workers favoured sterilisation of persons with intellectual disabilities as a form of birth control and that $75 \%$ of parents of children with intellectual disabilities were against their children marrying and raising children. This contrasts with their statistic that suggests that the majority of persons with mild intellectual disabilities want to marry and raise a child and it sits uneasily with the position already reached by the government in 2001 (Department of Health 2001) that intellectually disabled people should be enabled to develop a range of relationships, including ones of a physical and sexual nature. Nevertheless, as May \& Simpson (2003) comment, 'it remains the case that the majority of people with intellectual disabilities do not marry, have children or enjoy intimate relationships'. Furthermore, there is evidence of a higher prevalence of intellectually disabled parents entering care proceedings and losing care of their children (Booth 2004). As Healy et al (2009) comment, "whilst normalisation is espoused, it is rarely achieved'. This mirrors the observation of Bartlett et al (2010), when commenting on policies concerning sexuality and sexual expression, that 'the negative or prohibitive attitudes to sexual or emotional expression [...] suggest a hesitancy to

\section{BOX 2 Relevant Mental Capacity Act 2005 provisions}

- Capacity is presumed unless it is established that the person lacks it

- No finding of incapacity can be made unless all practicable steps to help the person make the decision have been unsuccessful

- Lack of capacity cannot be concluded merely because an unwise decision is made
As Brown (1994) notes, 'fear and myths about

engage with real situations'. As recently as 2016, the National Development Team for Inclusion (Harfleet 2016) found deep-seated negative attitudes towards people with intellectual disabilities when seeking to support them in developing sexual and romantic relationships.

\section{The relevant law}

The key statutes of relevance to the consideration of sexual rights are:

- the Mental Capacity Act 2005

- the Human Rights Act 1998

- the Sexual Offences Act 2003.

\section{The Mental Capacity Act}

As sexual expression and sexual activities involve decision-making, the Mental Capacity Act 2005 (the MCA) is of particular importance when deciding whether people with mental disorder or intellectual disability can make such decisions. Box 2 lists the relevant provisions. It is important to note that nothing in the MCA permits the Court of Protection, or a person acting in the best interests of a person who lacks capacity, to make a decision on consenting to marriage or a civil partnership or consenting to have sexual relations (s.27), although it does not preclude the Court of Protection from making a declaration under s. 15 with regard to a person's capacity to consent to such matters.

\section{The Human Rights Act}

The Human Rights Act 1998 gave effect to the ECHR, and specifically the right to respect for private and family life (Article 8), the right to freedom of thought, conscience and religion (Article 9) and the right to marry (Article 12).

Psychiatric patients and health and social service users have the same right to sexual relationships as other individuals. This right is founded in Article $8(1)$ - the right to respect for private and family life - without interference by public authority except such as is in accordance with the law. The cases of Niemitz v Germany (1993) and Re MM, Local Authority X v MM and KM [2007] make it clear that curtailment of sexual activity engages Article 8(1). capacity must be made in their best interests

- Before the acts or decisions are taken, purpose for which they are needed can be attained through a less restrictive way to give effect to the person's rights and freedom of action
- Acts or decisions for a person who lacks regard must be had as to whether the

\section{The Sexual Offences Act}

Part 1 of the Sexual Offences Act 2003 creates a number of offences against persons with a mental disorder that impedes their capacity for choice. Section 79(6) adopts the definition of mental disorder espoused in s.1 of the Mental Health Act 1983 and so a person with intellectual disability finds protection under the Sexual Offences Act. 
These offences include sexual activity with a person with a mental disorder that impedes choice (s.30) and causing or inciting a person with a mental disorder that impedes choice to engage in sexual activity (s.31). Under s.39, any sexual touching by a care worker of a person with a mental disorder is prohibited while that relationship of care continues (s.38). However, this prohibition does not apply if the person with mental disorder is aged 16 or over and the care worker is married to them (s.43(1)). Likewise, it does not apply where a lawful sexual relationship started before the care relationship (s.44(1)), as might be the case where someone who provides care, assistance or services to their partner continues to have a consensual sexual relationship following the onset of their partner's mental disorder. Section 39 makes it an offence for someone who provides care, assistance or services to a person with mental disorder and who knows, or reasonably is expected to know, that the person has a mental disorder to intentionally cause or incite that person to engage in a sexual activity with another person. This has implications for carers, whether health professionals or family members, who may be involved in obtaining the services of a prostitute for someone with a mental disorder. A carer who makes or promises payment for the sexual services of a prostitute is also at risk of prosecution if the prostitute has been subjected to exploitative conduct, whether or not the carer is aware that the prostitute has been so subjected (s.53A).

\section{Illustrative cases}

\section{Sexual relations}

'The issue of consenting to sexual relationships in vulnerable adults may be difficult for the person involved but also for those having to assess and advise.'

Curtice (2012)

As Sir Brian Leveson posited: 'When is it appropriate for society to intervene paternalistically in a decision or decisions that individuals make as to their sexual relations?' (IM $v$ LM [2014]). We review here a number of cases that illustrate the approaches adopted by the courts in recent years.

Mr Justice Munby discussed the capacity test in relation to sexual relations in $X$ City Council $v$ $M B, N B$ and $M A B$ (by his Litigation Friend the Official Solicitor) [2006], identifying the need for (a) an understanding of the sexual nature of the act and (b) knowledge and understanding that need not be complete or sophisticated and could be just sufficient rudimentary knowledge - what was later to be described as a 'very simple and low level test' ( $D$ Borough Council $v A B$ (Rev 1) (2011)). Mr Justice Munby held, as he had done earlier in Sheffield City Council v E and Another [2004] (see below), that these questions of capacity, be they about marriage or sexual relations, are 'issue specific'. So commenced a somewhat volatile debate within this area of law, ignited by Baroness Hale's dictum in $R_{V} C$ [2009]. She disagreed with $\mathrm{Mr}$ Justice Munby, arguing against 'issue specific' tests and instead preferring a 'person specific' reading of capacity in relation to sexual relations, since after all 'it is difficult to think of an activity which is more person and situation specific than sexual relations'.

London Borough of Ealing v KS \& Ors [2008] is a post-MCA case which importantly deals with the issue of fluctuating capacity. KS lived in a mixed-gender residential home. She had an intellectual disability and a chronic recurrent schizoaffective disorder. During relapses of psychosis she was particularly vulnerable in terms of her sexual behaviour. As there was evidence that any deterioration in her mental capacity was likely to occur over days rather than hours and be readily observable to her carers, the court concluded that they should be given a 'clear list of the indicators of a possible loss of capacity to make decisions about sexual intercourse or other sexual contacts, so that they may (a) recognise them and (b) act consistently with her other carers in establishing where the dial points on the barometer of capacity'. The judge recognised that there might well be periods when KS had the capacity to consent to sexual intercourse but might make some extremely unwise decisions as to the sexual activity undertaken. Albeit that she was a potentially vulnerable person even when she had capacity, the judge expressed the hope that the law would never come to the stage 'that it will seek to intervene to prevent acts on the part of the citizen which it does not consider to be in that citizen's best interests which are nevertheless lawful acts and which the citizen has the capacity to agree to'.

The case of $D$ Borough Council is important because it followed the implementation of the MCA in 2007 but, following much discussion, Mr Justice Mostyn was not persuaded that the MCA or its Code of Practice modified the pre-MCA case law. He set out a three-limbed test, concluding that the capacity to consent to sex required an understanding and awareness of:

(1) the mechanics of the act

(2) that there are health risks involved, particularly the acquisition of sexually transmitted and sexually transmissible infections

(3) that sex between a man and a woman may result in the woman becoming pregnant.

However, as the instant case illustrated (Box 3), there were 'potentially serious management 


\section{BOX 3 Capacity to consent to sexual relations}

In the case of $D$ Borough Council v $A B(\operatorname{Rev} 1)(2011)$, 'Alan' was 41 years old, his 10 was assessed as 48 and he was described as 'seriously challenged in all aspects of his mental functionality'. He lived in local authority accommodation, which he shared with 'Kieron'. Alan was described as having a 'vigorous sex drive' and he had engaged in sexual relations with males and females, including kissing, mutual masturbation and oral sex but apparently not heterosexual coitus. He engaged in penetrative anal sex with Kieron. Following some inappropriate and suggestive behaviour towards children, the local authority applied for an order authorising a restriction of contact with Kieron and another person so as to prevent sexual relations occurring. The court made an interim declaration that enabled Alan to be placed under such close supervision that he was prevented from engaging in any sexual activity other than private masturbation.

At the substantive hearing of his case, a psychiatrist gave evidence that Alan:

- had little or no idea what female genitalia were, or what they were for

- had no concept of sex being a reproductive function

- had no understanding at all of heterosexual coitus

- understood the mechanics of mutual masturbation and anal sex with persons of either gender
- had very limited and faulty knowledge of the health risks associated with sexual relations; he thought that sex could give you spots or measles

- knew what a condom was but was unable properly to put one on a prosthetic penis.

The judge therefore concluded that Alan did not have the capacity to consent to and engage in sexual relations. He made interim declarations that the local authority should provide Alan with sex education in the hope that he would gain the requisite capacity. There was to be a review of the effectiveness of the education in 9 months prior to making final declarations. problems where different kinds of sexual activities are practised at different times'. The judge doubted that the third criterion applied to penetrative anal and oral sex; he doubted whether the second or third were applicable to mutual masturbation. In the event, 'Alan' failed on all three criteria with regard to heterosexual penetrative vaginal sex. With regard to homosexual oral and anal sex, he failed on the second criterion. It was therefore concluded that he lacked the capacity to consent to and engage in sexual relations.

In 2012, Mr Justice Hedley had to decide whether 29-year-old H, who had intellectual difficulties and autism, possessed capacity to consent to sexual relations (A Local Authority v H [2012]). He noted that such questions are "clearly both sensitive and difficult', since such decisions are, after all, 'considerable incursions into personal autonomy and freedom'. Drawing on s.3(1) of the MCA, he concluded that:

'Clearly a person must have a basic understanding of the mechanics of the physical act and clearly must have an understanding that vaginal intercourse may lead to pregnancy. Moreover it seems to me that capacity requires some grasp of issues of sexual health.'

However, he went on to acknowledge that his following discussion on whether capacity should include 'the moral and emotional aspect of human sexual relationships [...] may have deepened rather than dispelled the legal fog in which this concept of capacity to consent to sexual relationships has drifted'.

The possible overcomplication of the capacity test in relation to sexual relations was met with disdain by many judges, such as Mr Justice Baker in $A$ Local Authority v TZ (by his Litigation Friend the Official Solicitor) [2013]. He commented that '[m] ost people faced with the decision whether or not to have sex do not embark on a process of weighing up complex, abstract or hypothetical information' and therefore 'the imposition of a higher standard for capacity may discriminate against people with a mental impairment'.

In the aforementioned case of $I M v L M$, Sir Brian Leveson discussed the apparent discord among judges as to the correct capacity test, be it issue specific or person specific. He fully supported Mr Justice Munby's issue-specific approach. A similar stance was also recently taken by Mrs Justice Parker in London Borough of Southwark $v$ KA and MA [2016]. She was against complicating the test as to capacity since this would 'involve necessary paternalism and a derogation from personal autonomy'. She regarded as unimportant the 'use and weigh' element of s.3(1) of the MCA in relation to sexual relations because of the circumstances in which such decisions are made, i.e. what is colloquially known as 'in the heat of the moment'. Instead, she emphasised that the relevant information that needs to be understood is rudimentary in nature:

- the mechanics of the act

- that the act can lead to pregnancy

- that there are health risks involved.

Thus, the courts in England and Wales apply capacity-based law to sexual relations but try to avoid requiring intellectually disabled individuals to engage in a level of decision-making that is not expected of people who do not have an intellectual disability. When it was suggested in $D$ Borough Council that part of the test should be an understanding that 'sex is part of having relationships with people and may have emotional consequences', Mr Justice Mostyn rejected this with the observation that 'a deal of sex takes place where one or other party is wholly oblivious to this supposed necessity'. 
So, the information that needs to be understood is set at a low level. We will see next that the threshold is equally modest should mentally disordered or intellectually disabled people decide to solemnise their relationship through marriage.

\section{Marriage}

Marriage is, simply, a contract. Such contracts raise issues for those with mental disorders or intellectual disabilities, who may lack the capacity to consent to such a contract.

As Mr Justice Munby held in Sheffield City Council $v$ E and Another [2004] when deciding whether E, a 21-year-old with hydrocephalus and spina bifida, could marry her 37-year-old boyfriend, who had a history of sexual violence, 'it is a general rule of English law, whatever the context that the test for capacity is the ability to understand the nature and quality of the transaction'. Therefore, the questions that need to be considered are:

- Does E understand the nature of the marriage contract?

- Does she understand the duties and responsibilities normally attached to marriage?

He concluded that 'the contract of marriage is in essence a very simple one which any person of normal intelligence can readily comprehend'. As the two questions above were answered in the affirmative, E was accordingly allowed to enter into the marriage contract with her boyfriend. $\mathrm{Mr}$ Justice Munby accurately saw the potential danger of setting 'the test to marry too high, lest it operate as an unfair, unnecessary and indeed discriminatory bar against the mentally disabled'.

This common law test has been supported in more recent cases, including $A, B \& C$ V X \& $Z$ [2012] and the aforementioned case of $L B$ Southwark $v K A$ and $M A$, where Mrs Justice Parker confirmed that the test for capacity to marry is indeed simple and uncomplicated (Box 4).

The law in this area thus seems clear cut. The courts are rejecting paternalism in favour of clear rules of contract to disallow the implementation of discriminatory, higher-standard tests which would unfairly disallow those with mental disorder or intellectual disability from entering a marriage contract.

These matters cannot be examined in isolation; indeed, they form part of a larger debate that includes the issues of those with mental disorders or intellectual disabilities starting a family. To these we turn next.

\section{Contraception}

Access to contraception amounts to access to medical treatment, therefore the individual seeking
BOX 4 Considerations in assessing capacity to marry

- Marriage is status specific and not person specific

- The wisdom of the marriage is not a relevant consideration

- The person must understand the broad nature of the marriage contract

- The person must understand the duties and responsibilities ordinarily associated with marriage

- The essence of marriage is for two individuals to live together and to love one another

- The person must not lack capacity to enter into sexual relations

(per Mrs Justice Parker in London Borough of Southwark v KA and MA [2016]]

contraception requires the capacity to do so. In the landmark decision of Gillick $v$ West Norfolk and Wisbech Area Health Authority [1986] the House of Lords found that contraception could be given to those under 16 years of age when the said child possessed the capacity to consent.

The key case in this area, A Local Authority v Mrs $A$ and $M r A$ [2010], concerned a 29-year-old woman who had an IQ of 53, which meant that 'her general cognitive ability [was] in the extremely low range of intellectual functioning'. Questions arose as to her capacity in relation to contraception, because of her problematic relationship with her husband. After hearing contradictory expert evidence, $\mathrm{Mr}$ Justice Bodey stated that 'the test for capacity should be so applied as to ascertain the woman's ability to understand and weigh up the immediate medical issues surrounding treatment'. What this would include was set out in the judgment (Box 5).

Indeed, in this case Mr Justice Bodey was against a broad reading of 'reasonably foreseeable consequences' as required by s.3(4) of the MCA, since it would 'set the bar too high and would risk a move away from personal autonomy in the direction of social engineering'. He rejected the argument that the 'reasonably foreseeable consequences' included being able to understand and envisage, if she decided against contraception and became pregnant, "what would actually be involved in caring for and committing to a child' or the wider 'social' ramifications of childbirth. Observing that in the real world, where appointments in surgeries and family planning clinics last perhaps less than half an hour, such a test could not be applied as there would be "no opportunity for a meaningful investigation as to the woman's background; nor as to the accuracy of what she told the practitioner [...] no 
BOX 5 Information relevant to making a decision about contraception

- The reason for contraception and what it does (which includes the likelihood of pregnancy if it is not in use during sexual intercourse)

- The types available and how each is used

- The advantages and disadvantages of each type

- The possible side-effects of each type and how they can be dealt with

- How easily each type can be changed

- The generally accepted effectiveness of each.

(A Local Authority v Mrs A and Mr A [2010])

opportunity for disclosure of medical or social services records about her background, nor for discussion about her with professionals or family members'. There has to be some limit in practice on what needs to be envisaged, if only for public policy reasons. Mr Justice Bodey's concern about a move away from personal autonomy in the direction of social engineering followed on from his observation that a requirement for the woman to understand enough about the realities of parenthood would enter the realms of a degree of subjectivity into which a paternalistic approach could easily creep and fall foul of the embargo in s.1(4) of the MCA against finding incapacity on the basis that a given decision would be 'unwise'. Preventing otherwise capacitous people from making unwise decisions would be social engineering.

\section{Termination of pregnancy}

Since the termination of a pregnancy, be it medicinally induced or surgical, involves medical treatment, the pregnant woman involved must have the capacity to consent to the treatment.

In Re SS [2001] Mr Justice Wall had to decide whether SS, a 34-year-old woman with schizophrenia detained in a psychiatric hospital, possessed the capacity to consent to a termination. Problematic in this case was the fact that SS was nearing the 24-week limit imposed by s.1(1)(a) of the Abortion Act 1967, which meant that the type of termination required was far more invasive. In assessing her best interests, Mr Justice Wall took into account her reportedly having said that sometimes 'she is worried that if she has the baby, she will kill it' and her having also 'described the baby as being dead'. Wall concluded that such a termination was not in SS's best interests, in opposition to her desires. He reasoned that termination at such a late stage would be painful and traumatic and she might later grieve over her loss. He also observed that none of the professional witnesses was able to say that a termination was likely to be less traumatic than a normal delivery followed by removal of the child. He noted that 'if the pregnancy is not terminated the applicant will be obliged to carry a child (which she does not want) to term'. However, he believed that this was unproblematic, considering that such threats as noted above would not come into fruition because 'she will remain subject to the detention under the Mental Health Act'.

More recently, in the case of NHS Trust $v$ P [2013], Mr Justice Hedley had to answer similar questions in regard to $\mathrm{P}$, who had 'a learning disability which places her intellectually in the bottom $1 \%$ of the population'. Hedley commented that when it comes to assessing capacity in light of the MCA, 'the intention of the Act is not to dress an incapacitous person in forensic cotton wool but to allow them [...] to make the same mistakes that all other human beings are at liberty to make'. He concluded, in reliance on the psychiatric assessment of $\mathrm{P}$, that she did possess the capacity to decide whether or not to terminate her pregnancy since she fulfilled the requirements as set out in s. 3 of the MCA. The concluding paragraph of his judgment informs consideration of many of the issues in this article (Box 6).

$\operatorname{Re} S B$ [2014] raises different issues. Mr Justice Holman's judgment focuses on the autonomy of the individual seeking an abortion. This was a 37-year-old woman with bipolar disorder. He highlights the need to avoid stepping in on such matters, when others would look at the outcome as unjust, relying on s.1(4) of the MCA to state that 'autonomy includes the autonomy to make a decision which may be unwise'. In disagreeing with the psychiatric assessments that SB lacked capacity, Mr Justice Holman decided that she did have the capacity to consent to a termination of pregnancy. He believed that the psychiatrists and hospital had set 'the level of the bar as to capacity' too high.

\section{Sterilisation}

The word sterilisation 'has come to carry emotive overtones' (Re B (A Minor) (Wardship: Sterilisation) [1987]) not least due to its intrinsic links to the eugenics movement that most prominently came to the fore in Nazi Germany. In Re B, Lord Bridge identified an urgent need for the judiciary to impress on the public that 'this case has nothing whatsoever to do with eugenic theory'. B, aged 17, had 'a moderate degree of mental handicap' and 'a very limited intellectual development'. B's sexual awareness and desires came to the fore, but she lacked the ability to understand contraception, so the court had to decide, using its wardship jurisdiction, whether sterilisation 
was the best route. In concluding in favour of sterilisation, Lord Oliver commented that 'the vulnerability of this young woman, her need for protection and the potentially frightening consequences of her becoming pregnant are not in doubt'.

Shortly after, in 1990, the House of Lords was confronted with a similar dilemma, this time concerning an adult (Re $F$ (A Mental Patient: Sterilization) [1990]). F was a 36-year-old woman with the mental age of a child of 4 to 5 . She was a voluntary in-patient at a mental hospital. The issue of sterilisation arose when she formed a sexual relationship with a male patient and it was believed that she would not be able to cope at all with pregnancy, labour or delivery. It would thereby be 'disastrous for her to conceive a child'. As courts do not have wardship jurisdiction for adults, the House of Lords had no power to consent to the operation as it was able to do in $\operatorname{Re} B$. Hence, it ruled that the issuance of a declaration of lawfulness or unlawfulness would be the appropriate route for such cases. Sterilisation would be lawful, as indeed was held in this case, if the procedure was in the patient's 'best interests' and this has been described as one which is carried out 'in order either to save [the individual's life], or to ensure improvement or prevent deterioration in [his or her] physical or mental health'. Lord Keith, when commenting on this case in Airedale NHS Trust $v$ Bland [1993], clarified that sterilisation was held to be in F's interest because 'her life would be fuller and more agreeable if she were sterilised than if she were not'.

It is worth noting the difference of approach adopted by the courts in relation to male and female patients up to the turn of the century. It seems that it was more likely for the courts to support sterilisation of a female patient compared with enforcing a vasectomy on a male patient. Sterilisation always seemed to be in the female's best interests but not so for males, as they cannot get pregnant.

To this day, the sterilisation of adults who lack capacity requires the prior sanction of a judge (Practice Note (Official Solicitor: Declaratory Proceedings: Medical and Welfare Decisions for Adults who Lack Capacity) [2006]). However, for over a decade after $\operatorname{Re} F$, it seems that sterilisation was only found to be in female patients' best interests: Re W (Mental Patient: Sterilisation) [1993], Re X (Adult Patient: Sterilisation) [1998], Re Z (Medical Treatment: Hysterectomy) [2000]. This was predicated on the risk of pregnancy. For males, where the risk of pregnancy was non-existent, sterilisation was not found to be in their best interests. This was discernible in $\operatorname{Re} A$ (Mental Patient: Male Sterilization) [2000], which concerned the proposed vasectomy of a 28 -year-old man, A, who had a

\section{BOX 6 Judgment of Mr Justice Hedley in NHS Trust v P [2013]}

'It is [...] very important to bear in mind, particularly in the field of those with significant learning difficulties who may well be unable to function independently in the community in every aspect of their life, that they may very well retain capacity to make deeply personal decisions about how they conduct their lives. One has in mind the question of choice of partners; the extent to which they wish to be sexually active; the extent to which they may wish to make permanent relationships by way of marriage or indeed civil partnership; the extent to which they may wish to be able to make decisions about their own medical care, including, as in this case, the continuation or termination of a pregnancy. It cannot be the case that merely because a person has significant difficulties in functioning in the community, it can be presumed that they lack capacity to make profoundly personal decisions. They may in fact do so but that has to be assessed on an individual basis.' 'severe impairment of intelligence'. His mother, who had cared for him, was suffering deteriorating health. She was worried that when A went into local authority care, he might enter into a sexual relationship with another resident that would result in the birth of a child for whom he could not take care. She applied to court for a declaration that a vasectomy operation could lawfully be performed on him. Relying on European case law, the Official Solicitor acting for A argued that 'there is a presumption against sterilisation of a mentally incapacitated patient on non-therapeutic grounds'. The 'best interests' test was discussed by Dame ButlerSloss, who asserted that it is based on 'that person and applied to the individual facts of the case'. The court found that sterilisation was not in A's best interests. Lord Justice Thorpe commented that if there are any opportunities of replacing with reality the fantasies that stimulate A's isolated masturbation and sexual activity then they should be grasped'. As observed by Barton-Hanson (2015), the strength of such rhetoric is somewhat limited by A's reality; as Lord Justice Thorpe commented, A's 'chances of forming a sexual relationship were slim'. Dame Butler-Sloss opined that 'sexual intercourse for a woman carries the risk of pregnancy which patently it does not for a man'. Should he enter into a sexual relationship, it is 'likely that the woman concerned would be the object of protection rather than A'.

At the turn of the century, there was what some, such as Barton-Hanson (2015), have called a 'paradigm shift' in relation to the sterilisation of those with intellectual disabilities. In the case of Re $S$ (Adult Patient: Sterilization: Patient's Best Interests) [2001] the Court of Appeal grappled with what was in the best interests of S, a 29-year-old woman with severe intellectual disabilities who was distressed by her menstrual periods. In deciding what was in a patient's best interests, Lord Justice Thorpe pointed out that this 'embraces issues far 
wider than the medical'. Judicial decisions will, according to Dame Butler-Sloss, incorporate broader ethical, social, moral and welfare considerations'. Given the availability of alternative methods of dealing with S's problem, hysterectomy was not pursued. Instead, the Mirena coil was inserted, with the option of a further hearing if this method was not sufficiently effective. It is nevertheless noteworthy that the focus in this case was not S's risk of pregnancy. In situations where a future risk of pregnancy poses a risk to the life of a mentally disordered or intellectually disabled woman, the court will not hesitate to sanction sterilisation: NHS Foundation v QZ (by her Litigation Friend, the Official Solicitor) [2017].

The broader considerations emphasised by the Court of Appeal in $\operatorname{Re} S$ resulted in sterilisation being approved for an incapacitous male patient in NHS Trust v DE [2013]. DE was nearly 37 years old at the time, but he had a mental age of between 6 and 9 years. Although he lived at home with his parents, he had maintained a 10-year-long loving relationship with PQ (who also had 'learning disabilities', albeit less severe), whom he visited regularly. Their relationship was a sexual one, resulting in the birth of a child, who had to be cared for by PQ's mother as they were both unable to do so. As DE found the birth of the child disruptive to his life, he expressed repeatedly his desire not to father any more children. The court held that a vasectomy was in his best interests. The reasons included that, if another child was born, DE would be deeply distressed and the removal of another child from PQ could lead to the breakdown of their relationship; and the sterilisation would allow him to continue his relationship with PQ as before. Alternative contraceptive routes were discussed, but Mrs Justice King concluded that it would be unrealistic to expect that DE's use of a condom would be other than unreliable at best'. She highlights the key parts of the MCA in relation to assessing what is in the individual's best interests (see s.1(5)). In weighing up what was in DE's best interests the court agreed with the parents that DE should undergo the vasectomy in order to allow minimum supervision and thus his 'independence' to be reinstated.

The question of the sterilisation of people with mental disorders or intellectual disabilities will be decided on the facts of each individual case. $D E$ shows that although DE is male and therefore not at risk of pregnancy, sterilisation is allowed. Unlike A, his risk of otherwise losing the relationship with PQ renders sterilisation in his best interests. Gender alone is no longer a determinant. Sterilisation can be sanctioned for males too, despite the absence of any risk of pregnancy, if this is in their best interests. With best interests encompassing considerations wider than just the medical, courts also now seem willing to consider alternatives to hysterectomy except where the pregnancy could be life-threatening.

\section{Parenting}

'A philosophical and practical shift in the approach to working with disabled parents is required [underpinned by] a recognition of the right of disabled people, within the bounds of current legislation, to be supported in fulfilling their roles and responsibilities as parents.'

Goodinge (2000) para. 1.7.

Parental mental disorder, particularly when it involves alcohol or other substance misuse, and parental intellectual disability are often issues in care proceedings in the family court, and research carried out in care and related proceedings before courts in Leeds and Sheffield (Booth 2004) has shown that only $10.2 \%$ of the children of parents with intellectual disabilities were rehabilitated with their parents. Four principal reasons were put forward to explain why: (a) severity - 'only the serious cases get to court so inevitably the likelihood of rehabilitation is slim'; (b) time scales - 'parents with learning difficulties are less likely than other parents to be able to change their ways in time to meet the developing child's needs'; (c) resources '[a] lack of family support and a lack of commitment to working with these families'; and (d) needs - 'the parents' needs are too great'.

In such cases the threshold criteria that must be fulfilled to make a care order or supervision order are set out in s.31(2) of the Children Act 1989:

'A court may only make a care order or supervision order if it is satisfied -

(a) that the child concerned is suffering, or is likely to suffer, significant harm; and

(b) that the harm, or likelihood of harm, is attributable to -

(i) the care given to the child, or likely to be given to him if the order were not made, not being what it would be reasonable to expect a parent to give him; or

(ii) the child's being beyond parental control.'

The case of Re L (A Child) (Care: Threshold Criteria) [2007] is illustrative of how the criteria were applied in a case involving intellectually disabled parents (Box 7). In this case, and in subsequent cases, the critical issue has been that of 'serious harm'. For example, in Buckinghamshire $C C$ v $C B$ (unreported, Family Court 23 July 2015) it was held that continual care by the intellectually disabled mother would be harmful to her child, who had a global developmental delay, and the level of support required by the mother to care for 
him would have been so extreme as to be detrimental to his welfare.

Commenting on Re L, Dimopoulos (2009) has expressed concern 'that the judicial reasoning focused selectively on specific facts of the case in relation to the harm the children were suffering, rather than addressing the parents' disability' and he has submitted that 'the element of disability requires a different approach from the court'. Such an approach, he submits, is suggested by the case of Kutzner v Germany (46544/99) [2003]. Therefore, the first step should be to provide intensive and individually tailored support to intellectually disabled parents and if this fails the second step is for social care to take a more active role in the upbringing and care that the children are receiving in order to avoid compulsory intervention. Only where harm to the children's welfare is so great that it disturbs the balance between the competing interests of the parents exercising their parental care free of interferences and the harm to the children's welfare should judicial intervention occur, with the possibility of removal from parental care. Such an approach would uphold the right to respect for the family life of intellectually disabled parents. Likewise, Booth et al (2004) have concluded that:

\begin{abstract}
'The application of the threshold criteria and the provision of supports to parents are intimately connected, vitally so in the case of parents with learning difficulties whose problems in parenting can be traced back to their disability [...]. [A]dequate supports protect against parenting breakdown [and] the additional difficulties parents with learning difficulties encounter in providing good-enough care [...] can be offset by compensatory services. Against this background, the failure to deliver support sets the family up to fail the threshold criteria.
\end{abstract}

There is the further problem that the standard for proving 'likely significant harm' is a lesser standard than the 'balance of probabilities' standard that is necessary for proving actual significant harm, so the local authority has to prove only that there is a real possibility of the feared harm (Booth 2004). Furthermore, the parents labour under what is effectively a reverse burden of proof, in that they have to demonstrate that the local authority's presumption of parental inadequacy is ill-founded. Not surprisingly, Booth et al (2004) regard it as 'an open question whether the right to family life for parents with learning difficulties under the Human Rights Act 1998 is compatible with [the] interpretation of the threshold test contained in the Children Act 1989'.

\section{Conclusions}

Societal attitudes can create obstacles to the pursuit of a sexual life by people with mental disorders or

intellectual disabilities, and in clinical practice there is a risk of setting the bar too high. Necessarily there has to be a consideration of whether the individual has the capacity to make decisions about sexual relations and other sexual or reproductive matters. Where the courts have to intervene, they recognise the risk of making paternalistic incursions into personal autonomy and freedom, and of setting a high bar that amounts to discrimination against the mentally disordered and intellectually disabled. Relying on the rhetoric of human rights, they apply what is in effect the concept of normalisation. Furthermore, the courts recognise that these sensitive and difficult decisions need to be assessed on an individual basis.

In our second article (Dewson 2018), we will describe approaches that can be taken to allow capacitous patients with mental disorder and health and social service users with intellectual disability to enjoy a sexual life, enter into a marriage or civil partnership and make decisions about contraception, the termination of pregnancy and sterilisation; and for those who lack capacity, assist as to their best interests in such matters, without infringing the rights of others or having their own rights infringed.

\section{References}

Aunos M, Feldman M (2002) Attitudes towards sexuality, sterilization and parenting rights of persons with intellectual disabilities. Journal of Applied Research in Learning Disabilities, 15: 285-96.

Bartlett P, Mantovani N, Cratsley K, et al (2010) 'You may kiss the bride, but you may not open your mouth when you do so': policies concerning

\section{BOX 7 Application of the 'threshold criteria' to parenting by intellectually} disabled parents

In the case of Re L (A Child) (Care: Threshold Criteria) [2007], the intellectually disabled parents of two children had received support from social services for a number of years. The family had come to their attention when the elder child was sexually assaulted by an offender whom the father had invited to stay in the family home. Subsequently there were allegations of domestic violence inflicted on the mother by the father and an allegation that the father had been beating the children with a belt. As a result, the children were removed from the family home under an emergency protection order. There was also evidence of worrying instances of lack of boundaries between parents and children; bad language and bad behaviour of the children seemed to go unchecked by the father; and the children were encouraged to kick their mother. In quashing the order, the court
MCO answers

1 e 2 c 3 b $4 d \quad 5 c$ 
sex, marriage and relationships in English forensic psychiatric facilities. Liverpool Law Review, 31: 155-76.

Barton-Hanson R (2015) Sterilisation of men with intellectual disabilities: whose best interests is it anyway? Medical Law International, 15: 49-73.

Beauchamp TL, Childress JF (2013) Principles of Biomedical Ethics (7th edn). Oxford University Press.

Booth T, Booth W, McConnell D (2004) Parents with learning difficulties, care proceedings and the family courts: threshold decisions and the moral matrix. Child and Family Law Quarterly, 16: 409-21.

Brown $H$ (1994) An ordinary life? A review of the normalisation principle as it applies to the sexual options of people with learning disabilities. Disability and Society, 9: 123-40.

Craft A (1987) Mental handicap and sexuality: issues for individuals with a mental handicap, their parents and professionals. In Mental Handicap and Sexuality (ed A Craft). Costello.

Curtice M, Mayo J, Crocombe J (2012) Consent and sex in vulnerable adults: a review of case law. British Journal of Learning Disabilities, 41: 280-7.

Department of Health (2001) Valuing People: A New Strategy for Learning Disability for the 21st Century ( $\mathrm{Cm} \mathrm{5086).} \mathrm{The} \mathrm{Stationery}$ Office (TSO)

Dewson H, Rix KJB, Le Gallez I, Choong K (2018) Sexual Rights, Mental Disorder and Intellectual Disability: Practical Implications for Policy Makers and Practitioners.

Dimopoulos A (2009) Intellectually disabled parents before the European Court of Human Rights and English courts. European Human Rights Law Review, 1: 70-83.

Fernald WE (1893) The history of the treatment of the feeble-minded. In The History of Mental Retardation: Collective Papers (Vol. I) (eds M Rosen, GR Clark, MS Kivitz). University Park Press.

Goodinge S (2000) A Jigsaw of Services: Inspection of Services to Support Disabled Adults in their Parenting Role. Social Services Inspectorate.

Harfleet N, Turner S (2016) Supporting People with Learning Disabilities to Develop Sexual and Romantic Relationships. National Developmental Team for Inclusion.

Healy E, McGuire BE, Evans DS, et al (2009) Sexuality and personal relationships for people with an intellectual disability. Part I: Service-user perspectives. Journal of Intellectual Disability Research, 53: 905-12.

Maslow AH (1943) A theory of motivation. Psychological Reviews, 50 370-96

Maslow AH (1954) Motivation and Personality. Harper and Row.

May D, Simpson MK (2003) The parent trap: marriage, parenthood and adulthood for people with intellectual disabilities. Critical Social Policy, 23: 25-43

McCann E (2000) The expression of sexuality in people with psychosis: breaking the taboos. Journal of Advanced Nursing, 32: 132-8.

Tennille J, Wright E (2013) Addressing the Intimacy Interests of People with Mental Health Conditions: Acknowledging Consumer Desires, Provider Discomforts, and System Denial. Temple University Collaborative on Community Inclusion of Individuals with Psychiatric Disabilities.
World Health Organization (2006) Defining Sexual Health: Report of a Technical Consultation on Sexual Health 28-31 January 2002. WHO

Yates PM, Prescott DS (2011) Applying the Good Lives Model to clinica practice: redefining primary human goods. NOTA News. National Organization for the Treatment of Abusers (NOTA)

\section{Law reports}

$A, B \& C \vee X \& Z$ [2012] EWHC 2400 COP.

A Local Authority v H[2012] EWHC 49 COP.

A Local Authority v Mrs A and Mr A [2010] EWCA 1549 Fam.

A Local Authority v TZ (by his litigation friend the Official Solicitor) [2013] EWHC 2322 COP.

Airedale NHS Trust v Bland [1993] 1 All ER 821.

D Borough Council v AB (Rev 1) (2011) EWHC 101 (COP).

Gillick v West Norfolk and Wisbech Area Health Authority [1986] 1 AC 112.

IM v LM [2014] EWCA Civ 37.

Kutzner v Germany (46544/99) [2003] 1 FCR 249 (ECHR).

London Borough of Ealing v KS \& Ors [2008] EWHC 636 (Fam).

London Borough of Southwark v KA and MA [2016] EWCOP 20

Munjaz v United Kingdom [2012] MHLR 351; [2012] ECHR 1704.

NHS Foundation v OZ (by her litigation friend, the Official Solicitor) [2017] EWCOP 11.

NHS Trust v DE [2013] EWHC 2562 Fam.

NHS Trust $v$ P[2013] EWHC 50 COP.

Niemitz v Germany (1993) 16 EHRR 97.

Practice Note (Official Solicitor: Declaratory Proceedings: Medical and Welfare Decisions for Adults who Lack Capacity) [2006] 2 FLR 373.

Re A (Mental Patient: Male Sterilisation) [2000] 1 FLR 549

Re B (A Minor) (Wardship: Sterilisation) [1987] 2 WLR 1213

Re F (A Mental Patient: Sterilisation) [1990] 2 AC 1

Re L (A Child) (Care: Threshold Criteria) [2007] 1 FLR 2050 (Fam Div). Re MM, Local Authority X v MM and KM [2007] EWHC 2003 (Fam). Re S (Adult Patient: Sterilisation: Patient's Best Interests) [2001] Fam 15. Re SB [2014] EWHC 1417 COP.

Re SS [2001] 1 FLR 445

Re W (Mental Patient: Sterilisation) [1993] 1 FLR 381.

Re X (Adult Patient: Sterilisation) [1998] 2 FLR 1124.

Re Z (Medical Treatment: Hysterectomy) [2000] 1 FLR 523.

$R \vee C$ [2009] UKHL 42.

Sheffield City Council v E and Another [2004] EWHC 2808 (Fam).

$X$ City Council v MB, NB and MAB (by his litigation friend the Official Solicitor) [2006] EWHC 168 Fam. 
MCOs

Select the single best option for each question stem

1 'The right to pursue a satisfying, safe and pleasurable sexual life':

a was formulated by Baroness Hale in R v C [2009]

b is defined in Article 8(1) of the European Convention on Human Rights

c was first described in 1954 by Maslow

d is incorporated in article 9 of the European Convention on Human Rights

$\mathrm{e}$ is recognised by the World Health Organization.

2 Probable barriers to the right to pursue a satisfying, safe and pleasurable sexual life on the part of an individual with mental disorder or intellectual disability include:

a the paternalistic judgments of the courts in cases where the issue is the capacity to consent to a contract of marriage

b the Good Lives Model of rehabilitation

c the majority of parents of children with intellectual disabilities being against them marrying and raising children d Article 8(2) of the European Convention on Human Rights

e section 43(1) of the Sexual Offences Act 2003.

3 The capacity to engage in penetrative sexual relations:

a requires the weighing up of complex, abstract and hypothetical information

b requires some grasp of issues of sexual health

c depends critically on the 'use and weigh' element of s.3(1) of the Mental Capacity Act

$d$ requires an understanding of the sexual nature of the act and knowledge and understanding of sexual matters that are more than rudimentary

e cannot be separated from the capacity to consent to the contract of marriage.

4 Making a decision about contraception requires an understanding of:

a the broad nature of the marriage contract on the part of the individual concerned b the permanency of hysterectomy on the part of the individual concerned

c eugenic theory on the part of the clinical team

$d$ the advantages and disadvantages of each type on the part of the individual concerned

e Article 9 of the European Convention on Human Rights on the part of the clinical team.

5 In matters relating to the sterilisation of people with a mental disorder or intellectual disability:

a the courts place great weight on eugenic theory

b sterilisation of males is not permitted because males cannot get pregnant

c the prior sanction of a judge is required for the sterilisation of adults who lack capacity

$d$ the courts exercise a wardship jurisdiction for adults

e judicial decisions are made solely on medical grounds, as the courts are unable to incorporate broader ethical, social, moral and welfare considerations. 